\title{
Technical Note: Linking climate change and downed woody debris decomposition across forests of the eastern United States
}

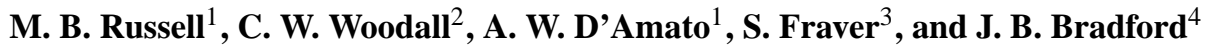 \\ ${ }^{1}$ Department of Forest Resources, University of Minnesota, St. Paul, Minnesota, USA \\ ${ }^{2}$ USDA Forest Service, Northern Research Station, St. Paul, Minnesota, USA \\ ${ }^{3}$ School of Forest Resources, University of Maine, Orono, Maine, USA \\ ${ }^{4}$ US Geological Survey, Southwest Biological Science Center, Flagstaff, Arizona, USA
}

Correspondence to: M. B. Russell (russellm@umn.edu)

Received: 27 April 2014 - Published in Biogeosciences Discuss.: 13 June 2014

Revised: 21 October 2014 - Accepted: 27 October 2014 - Published: 26 November 2014

\begin{abstract}
Forest ecosystems play a critical role in mitigating greenhouse gas emissions. Forest carbon $(\mathrm{C})$ is stored through photosynthesis and released via decomposition and combustion. Relative to $\mathrm{C}$ fixation in biomass, much less is known about $\mathrm{C}$ depletion through decomposition of woody debris, particularly under a changing climate. It is assumed that the increased temperatures and longer growing seasons associated with projected climate change will increase the decomposition rates (i.e., more rapid $\mathrm{C}$ cycling) of downed woody debris (DWD); however, the magnitude of this increase has not been previously addressed. Using DWD measurements collected from a national forest inventory of the eastern United States, we show that the residence time of DWD may decrease (i.e., more rapid decomposition) by as much as $13 \%$ over the next 200 years, depending on various future climate change scenarios and forest types. Although existing dynamic global vegetation models account for the decomposition process, they typically do not include the effect of a changing climate on DWD decomposition rates. We expect that an increased understanding of decomposition rates, as presented in this current work, will be needed to adequately quantify the fate of woody detritus in future forests. Furthermore, we hope these results will lead to improved models that incorporate climate change scenarios for depicting future dead wood dynamics in addition to a traditional emphasis on live-tree demographics.
\end{abstract}

\section{Introduction}

Live and dead trees are thought to contain $\sim 60 \%$ of forest $\mathrm{C}$ in mature forests, while soil and litter pools contribute the remaining $\sim 40 \%$ (Ryan et al., 2010). In particular, downed woody debris (DWD) is an important component of overall C stocks, accounting for approximately $20 \%$ of total C in oldgrowth (Harmon et al., 1990) and secondary (Bradford et al., 2009) forests. Whether measured in terms of decay rates, $C$ flux, and/or residence time ( $T_{\mathrm{RES}}$; the number of years until a DWD piece loses structural integrity and transitions to another ecosystem pool), previous investigations have quantified DWD $\mathrm{C}$ depletion in many regions and forest types (Fraver et al., 2013; Mackensen et al., 2003; Radtke et al., 2009; Russell et al., 2014). The potential for altered decomposition is well recognized for $\mathrm{C}$ stored in soil (Conant et al., 2011; Davidson and Janssens, 2006; Giardina and Ryan, 2000) and litter (Brovkin et al., 2012; Prescott, 2010); however, the impact of changing environmental conditions on DWD debris dynamics remains largely unexplored. While it has been shown that fungal colonization and termite biomass account for nearly three-quarters of the variability in wood decomposition on the local scale (Bradford et al., 2014), the factors driving variability on regional scales remain largely unexplored, particularly under changing environmental conditions. It is essential to understand and quantify these temporal patterns as DWD represents not only a substantial C pool but also facilitates tree regeneration, is a determinant of fire behavior, and serves as a vital wildlife habitat whose dynamics may be altered under future climates. 
Although DWD decomposition is included in a variety of ecosystem simulation models primarily through their relationship with temperature (e.g., Kirschbaum, 1999; White et al., 2000), the degree to which DWD decomposition may be altered under potential global-change scenarios remains to be quantified and incorporated into projections of longterm forest $\mathrm{C}$ dynamics. One unknown is the influence that projected future climates may have on DWD decomposition rates. The importance of temperature and moisture as drivers of DWD decomposition is well established (Edmonds et al., 1986), underscoring the potential for climate change to alter the future dynamics of this critical ecosystem component. Increased rates of decomposition will likely reduce the duration that woody debris is available for dead wood-dependent organisms (Mazziotta et al., 2014). Woody-detritus decomposition rates depend not only on climate but also on DWD size and condition, the decomposer community, and geographic locale (Bradford et al., 2014; Brovkin et al., 2012; Fraver et al., 2013; Radtke et al., 2009; Russell et al., 2013; Russell et al., 2014). Specifically, the eastern United States has experienced increased mean annual temperatures (MAT) throughout much of the region over the past century, with the exception of the southeast, which is characterized by both cooling winters and warmer summers (Zhu et al., 2012). woody debris decomposition rates should be sensitive to these changes in MAT (Brovkin et al., 2012), recognizing that local-scale factors additionally contribute to determining wood decay patterns (Bradford et al., 2014). To accurately represent DWD dynamics in ecosystem processes, models should be sensitive to transient responses, such as changes in disturbance regimes, when depicting the nonlinear patterns inherent in DWD decomposition (Harmon et al., 2011a).

Our objective was to link current and future climate information with models representing woody debris decomposition to quantify potential future changes in temporal DWD dynamics in forests of the eastern US. Specific objectives were to (1) compare differences in DWD residence time assuming a static versus dynamic climate throughout the duration of decomposition and (2) forecast ecosystem-level C flux for DWD using the static- and dynamic-climate scenarios.

\section{Methods}

\subsection{Study area}

The geographic scope investigated here ranged eastward from the US state of Minnesota to Maine in the north and Louisiana and Georgia in the south (latitude range from 29.56 to $48.74^{\circ} \mathrm{N}$; longitude range from 67.06 to $96.71^{\circ} \mathrm{W}$ ). Data from the eastern US are employed because remeasurement data have been collected in the region which have informed DWD modeling efforts (e.g., Russell et al., 2013), whereas remeasurement data are not yet available for west- ern US states. Forest types across this region varied in terms of species assemblage, forest productivity potential, and climate. More than 75 forest types were identified by the US Department of Agriculture Forest Service's Forest Inventory and Analysis (FIA) program across the study area, which represented 14 broader forest type groups (Woudenberg et al., 2010).

\subsection{Data}

Data used to simulate the decomposition of woody debris were obtained from a DWD inventory conducted in 2001 on 516 FIA plots across the eastern US (Russell et al., 2014). Each plot consisted of four $7.32 \mathrm{~m}$ fixed radius subplots for a total plot area of approximately 0.07 ha, where tree and site attributes were measured. Downed woody pieces were defined as DWD in forested conditions if they had a diameter greater than $7.62 \mathrm{~cm}$ along a length of at least $0.91 \mathrm{~m}$. All plots displayed a minimum of at least one DWD piece that met this definition. Individual DWD pieces were sampled using a line-intercept sampling method (Van Wagner, 1968) on $18.0 \mathrm{~m}$ horizontal distance transects radiating from each FIA subplot center at azimuths of 30,150 , or 270 degrees. Only two transects from the three azimuths were sampled within each subplot, depending on spatial arrangement $\left(30^{\circ}\right.$ and $150^{\circ}$ for north and southeast subplots; $150^{\circ}$ and $270^{\circ}$ for center and southwest subplots); these transects totaled $143.6 \mathrm{~m}$ for an entire inventory plot. Data collected on each DWD piece included small-end and large-end diameters, decay class (DC), length (LEN), species, and piece location (i.e., plot, subplot, and transect number; horizontal distance along a sampling transect). In the field, DC was assigned to each DWD piece using a five-class system, with 1 being least and 5 being most decayed. Piece LEN was defined as the total length of the log in meters. In total, 4384 DWD pieces were collected from 32 conifer and 87 hardwood species as part of the inventory.

Climate information was obtained by specifying the latitude, longitude, and elevation of each FIA plot location to a spline surface model developed from climate station data across forests of North America (Table 1; Fig. 1) (Rehfeldt, 2006; US Forest Service, 2014). Downscaled predictions from 17 Coupled Model Intercomparison Project (CMIP5) model outputs were used to assess differences in DWD decomposition rates resulting from future climate predictions: Representative Concentration Pathway (RCP) 4.5, RCP 6.0, and RCP 8.5 (Intergovernmental Panel on Climate Change, IPCC, 2013). Downscaled General Circulation Model (GCM) data were obtained from the Moscow (Idaho) Forestry Sciences Laboratory (http://forest.moscowfsl.wsu. edu/climate); they were produced by adapting spline surfaces from present-climate data to GCM predictions (Rehfeldt, 2006). 

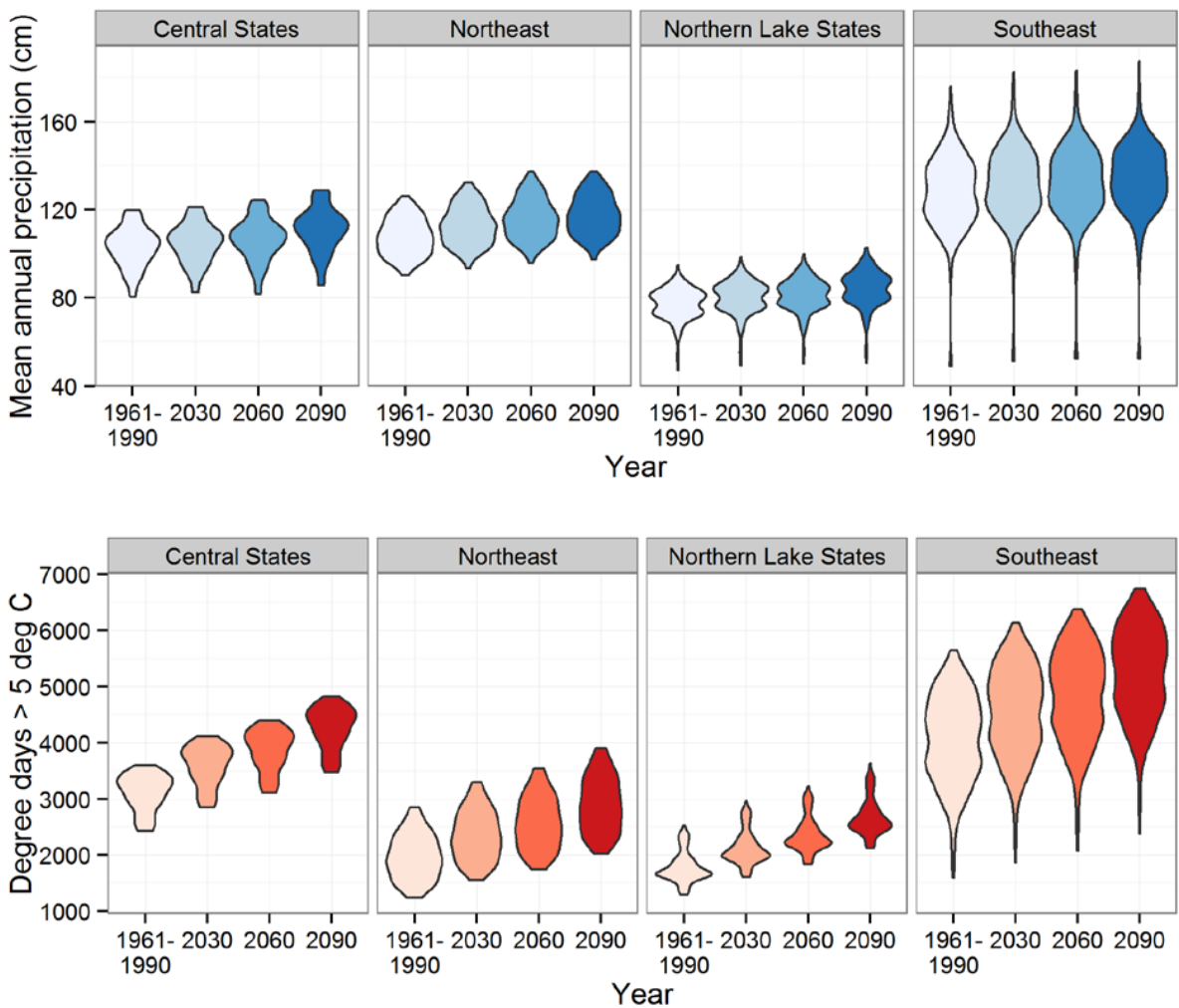

Figure 1. Violin plots of precipitation and degree day trends for study plots by geographic region across the eastern US for the climate normal period (1961-1990) and projected climates using an ensemble of 17 GCMs for CMIP5 models and an RCP 6.0 scenario.

Table 1. Current climate conditions for 516 plot locations using the US Forest Service Moscow Laboratory climate model (http://forest. moscowfsl.wsu.edu/climate/) for determining differences in downed woody debris decomposition dynamics across the eastern US.

\begin{tabular}{lllrrrr}
\hline Variable & Definition & Units & Mean & SD & Min & Max \\
\hline DD5 & Annual degree days & $>5{ }^{\circ} \mathrm{C}$ & 2667.6 & 915.2 & 406.0 & 5669.0 \\
MAP & Mean annual precipitation & $\mathrm{mm}$ & 869.8 & 360.2 & 219.0 & 3282.0 \\
MAT & Mean annual temperature & ${ }^{\circ} \mathrm{C}$ & 9.2 & 4.3 & -0.3 & 20.6 \\
MTCM & Mean temperature in the coldest month & ${ }^{\circ} \mathrm{C}$ & -5.3 & 6.6 & -18.0 & 12.7 \\
MTWM & Mean temperature in the warmest month & ${ }^{\circ} \mathrm{C}$ & 22.5 & 3.2 & 9.3 & 28.9 \\
\hline
\end{tabular}

\subsection{Analyses}

Decay class transition models were used to project the mass loss of DWD (Russell et al., 2013). Here, DC transition was defined as the probability that a DWD piece would remain in the same DC or advance to subsequent DCs at repeated inventories. These DC transitions were estimated as a function of climate (as measured in the number of degree days greater than $5{ }^{\circ} \mathrm{C}$ [DD5] observed in the FIA plot), LEN, and DC (Russell et al., 2013). Given the relationship between log size and woody debris decomposition (Cornwell et al., 2009; Janisch et al., 2005; Mackensen et al., 2003), LEN was used as a predictor in the DC transition model. We assumed a conic-paraboloid form (Fraver et al., 2007) to estimate the initial volume (Vol) of each DWD piece. Initial density (ID; $\mathrm{kg} \mathrm{m}^{-3}$ ) for an individual species $m$ (Harmon et al., 2008) and the appropriate DC reduction factor (DCRF) for DWD of a given species group $n$ in a DC $k$ (Harmon et al., 2011b) was obtained to estimate losses in wood density. To accurately represent DWD mass loss, a volume reduction factor (VRF) was subsequently applied to account for structural reductions in DWD Vol as decay progresses. We applied a VRF of $1,1,1,0.800$, and 0.412 for DC $1,2,3,4$, and 5 pieces, respectively (Fraver et al., 2013). Hence, DWD mass was calculated as:

Mass $=\mathrm{ID}_{m} \times \mathrm{DCRF}_{\mathrm{kn}} \times \mathrm{Vol} \times \mathrm{VRF}_{k}$,

where all variables are as previously defined.

A Monte Carlo simulation framework was used to estimate DWD Mass in 5-year intervals using the DC 
transitionequations (Russell et al., 2013; Russell et al., 2014). For the simulations, 1000 runs were carried out for 200 years to introduce uncertainty in estimating DC changes. This method involved simulating the DWD pieces by first assuming they were non-decayed, then drawing a random number from a uniform distribution and comparing it to the cumulative 5-year probability predicted using the DC transition model. Downed woody debris DC transitions were estimated by predicting the cumulative probabilities of pieces advancing in decay using a cumulative link mixed model. Cumulative link models (CLMs) are a type of ordinal regression model in which response variables are considered categorical or ordered (Agresti, 2007). The variables DD5, LEN, and initial DC were used to indicate decomposition potential across the eastern US and thus estimate DWD DC transitions (Russell et al., 2014):

$\log \left(\gamma_{i k j}\right)=\theta_{k}-\beta_{1}$ DD5 $-\beta_{2}$ LEN $-u$ ForType $_{j}+\varepsilon$,

where $\theta_{k}$ is the intercept term for DC $k$ (i.e., DC 1, DC 2, DC 3, DC 4, or DC 5), $\gamma$ is the cumulative probability for DWD piece $i$ moving through each of the successive $k$ decay classes within each ForType $j, \beta_{i}$ are the parameters estimated for conifer and hardwood species separately, and $\varepsilon$ is the random residual term. The random effect $u$ was specified to represent forest-type-specific effects on the DC transition process. The finding that LEN was a more effective predictor of decomposition than log diameter in these DC transition models is consistent with other studies that suggested a lack of a consistent relationship between log diameter and woody debris decomposition (e.g., Harmon et al., 1987; Radtke et al., 2009).

Predictions were accomplished by applying the DWD DC transition equations (Russell et al., 2013) to the data described above using the simulation framework. For each of the 4384 DWD pieces, a 1000-run Monte Carlo simulation was performed up to 200 years.

We assumed DWD would decay according to one of two scenarios: (1) a fixed (i.e., static) climate throughout the timespan of DWD decomposition or (2) a dynamic climate throughout DWD decomposition depending on the future climate predicted at each FIA plot location.

\subsection{DWD decomposition scenarios}

\subsubsection{Baseline}

For a baseline scenario, a static climate was assumed throughout the timespan of DWD decomposition. Hence, the independent variable DD5 used to represent climate regime in the DWD DC equation was held fixed and assumed to be the 30-year (1961-1990) normal, depending on its location within the region. To compare relative differences in DWD decomposition, pieces were separated into species group (i.e., conifer and hardwood species) and geographic region (i.e., north and south; Supplement Table S1). Smaller
Table 2. Baseline estimates of downed woody debris residence times, assuming a static-climate scenario.

\begin{tabular}{llrcr}
\hline Species group & Region & $n$ & \multicolumn{2}{l}{ Residence time (years) } \\
\cline { 3 - 5 } & & & Mean & SD \\
\hline \multirow{2}{*}{ Conifers } & North & 1648 & 87.4 & 13.0 \\
& South & 490 & 49.9 & 7.5 \\
\hline \multirow{2}{*}{ Hardwoods } & North & 1581 & 80.0 & 16.4 \\
& South & 665 & 51.6 & 11.0 \\
\hline
\end{tabular}

Baseline estimates assume a static-climate scenario throughout the duration of decomposition, assumed to be the 30-year (1961-1990) normal, depending on the number of degree days (DD5) $>5^{\circ} \mathrm{C}$ for each plot location; $n$ is the number of observations.

sample sizes for some species (e.g., $<10$ DWD pieces) constrained us to analyze relative differences according to the general species group.

Simulating the DWD pieces allowed us to approximate the number of years in which the proportion of biomass remaining attained any specified proportion. Residence time ( $\left.T_{\mathrm{RES}}\right)$ was calculated as the number of years in which the mean proportion of biomass remaining fell within one standard error of the mean for a decay class $5 \log$ (Russell et al., 2014). From a biological perspective, $T_{\mathrm{RES}}$ might be used as a surrogate for the number of years until a DWD piece loses all structural integrity and transitions to another population (i.e., another $\mathrm{C}$ pool). At this point, the DWD piece may be incorporated into the soil organic horizon and thus no longer meets the criteria for being inventoried as DWD within the FIA protocol (exclusive of combustion or harvest removal).

\subsubsection{Future climate}

For a changing-climate scenario, a dynamic climate was assumed to occur throughout DWD decomposition. Current CMIP5 models (Taylor et al., 2012) as described in the fifth assessment report (AR5) of the IPCC (2013) were obtained using three scenarios (RCP 4.5, RCP 6.0, RCP 8.5; US Forest Service, 2014). An ensemble of 17 AR5 model predictions was used for each RCP scenario (Supplement Table S2). Given that the DC transition equation operated on a 5-year interval, while climate information was provided for the 30year normal (1961-1990) and years 2030, 2060, and 2090, values for the DD5 variable were assumed to transition linearly between 2001 and 2030, 2030 and 2060, 2060 and 2090 , and post-2090 (if $T_{\text {RES }}$ was not yet reached by the year 2090). Within the simulation, a dynamic DD5 variable resulted in different values for $T_{\mathrm{RES}}$ and $\mathrm{C}$ flux when compared to the baseline scenario.

Projected changes in temperature (i.e., DD5) were more apparent at these sites compared to variables representing moisture, such as mean annual precipitation (MAP). Comparing the 30-year normal with the projected 2090 climate, DD5 would increase on average by $39.1 \%(\mathrm{SD}=10.8 \%)$, 

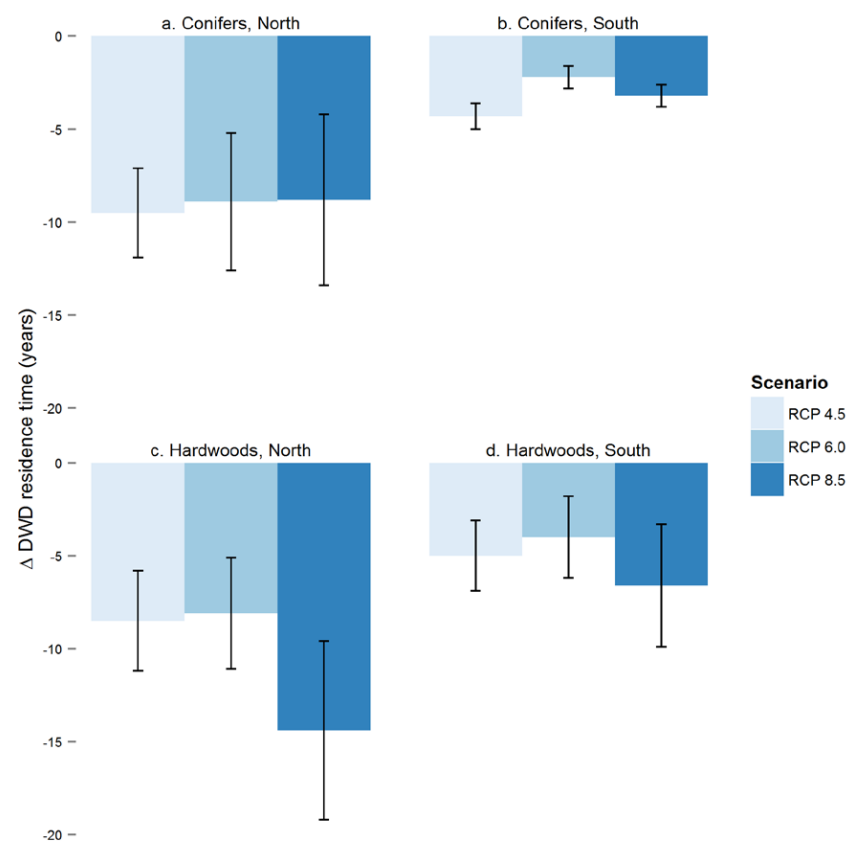

Figure 2. Decreases in downed woody debris (DWD) residence time compared to baseline scenario. Mean values by species group and region in eastern US forests for a baseline current-climate scenario and assuming changes in future climate (based on three RCP scenarios from an ensemble of 17 CMIP5 models). Error bars indicate one standard deviation.

while MAP is projected to increase by only $7.2 \mathrm{~cm}$ or $7.1 \%$ $(\mathrm{SD}=2.8 \%)$. Regionally, increases in the percent difference in current versus projected DD5 would range from as low as $29.3 \%(\mathrm{SD}=5.4 \%)$ in the southeast to as high as $51.2 \%$ $(4.5 \%)$ in the Northern Lake States (Fig. 1). Hence, in the absence of local-scale factors to use as a surrogate for decomposition (e.g., Bradford et al., 2014), temperature differences under future-climate scenarios may be employed to explain DWD flux across the eastern US at least in part.

\subsubsection{C flux}

To scale our estimates of $T_{\text {RES }}$ changes for DWD pieces, we forecasted an ecosystem-level DWD C flux. This was accomplished by projecting current DWD stocks inventoried from 2007-2011 (hereafter termed "year 2010") by the FIA program in 29 eastern US states (Woodall et al., 2013). These data were collected in a similar manner to the 2001 data, with the primary difference being that DWD was sampled along three $7.32 \mathrm{~m}$ transects at each of four subplots, totaling $87.8 \mathrm{~m}$ for a complete FIA plot (Woodall and Monleon, 2008).

Current DWD C stocks were first estimated by multiplying plot-level biomass values by a $\mathrm{C}$ concentration constant of $0.5\left(\mathrm{Mg} \mathrm{ha}^{-1}\right)$, followed by a simulation of DWD pieces. Carbon stocks in the DWD pool were then estimated in 5year time steps from 2010 onward. Assuming no inputs into the DWD pools over a 100-year span, C flux was defined as the amount of $\mathrm{C}$ lost for each 5-year span $\left(\mathrm{Mg} \mathrm{ha}^{-1} / 5\right.$ year). If the estimate of $T_{\mathrm{RES}}$ for a given species was exceeded by the number of simulation years, then it was assumed that the piece had completely decomposed (i.e., biomass was set equal to 0 ). Means for $\mathrm{C}$ flux were summarized by general forest type group (i.e., conifer and hardwood) following multiple simulation runs.

\section{Results}

Baseline estimates of $T_{\mathrm{RES}}$ ranged from $49.9 \pm 7.5$ years (mean $\pm \mathrm{SD}$ ) for conifer species in the southern US to $87.4 \pm 13.0$ years for conifer species in the northern regions (Table 2). For all RCP scenarios, $T_{\text {RES }}$ was predicted to decrease for all species groups and regions compared to the baseline scenario (see Table 3 for RCP 6.0). Decreases in $T_{\text {RES }}$ were generally less than 10 years for southern species, while northern species displayed greater decreases. The decrease in $T_{\mathrm{RES}}$ for smaller DWD pieces was generally less than 10 years. However, in some cases the decrease in $T_{\text {RES }}$ exceeded 20 years for larger DWD ( $>20 \mathrm{~m}$ in length) pieces located in the north (Table 3 ).

We estimated that the mean decrease in $T_{\mathrm{RES}}$ was greatest for northern hardwood species. When averaged across all climate models, the maximum mean decrease for this group was $10.3 \pm 3.5$ years, or a decrease of $13 \%$. Decreases in $T_{\text {RES }}$ were lowest for both southern conifer species, where a $6 \%$ decrease was found, followed by northern conifer and southern hardwood species (10\%; Fig. 2).

Carbon flux was initially greater for RCP scenarios compared to the baseline scenario (Fig. 3). For conifer forest types during the first 5 years, flux ranged from $-0.23 \pm 0.05 \mathrm{MgCha}^{-1}$ when considering an RCP 6.0 scenario to $-0.26 \pm 0.05 \mathrm{MgC} \mathrm{ha}^{-1}$ considering an RCP 8.5 scenario. Similarly, flux ranged from $-0.50 \pm 0.10 \mathrm{Mg} \mathrm{Cha}^{-1}$ when considering the baseline scenario to $-0.56 \pm 0.08 \mathrm{MgCha}^{-1}$ for an RCP 8.0 scenario in hardwood forest types during the first 5 years. Carbon flux generally tended to decrease more rapidly throughout the duration of the simulation (e.g., from 2015 to 2095) for RCP scenarios when compared to that of the static baseline climate assumption.

\section{Discussion}

Our study suggests that increased decomposition rates as resulting from future climate changes will decrease DWD residence times and increase initial $\mathrm{C}$ emissions from decaying logs. These findings have direct implications for modeling $\mathrm{C}$ dynamics from DWD under future global-change scenarios and suggest that future forest management and conservation activities may need to proactively manage for DWD to maintain contemporary levels. Given the range in climate and total 


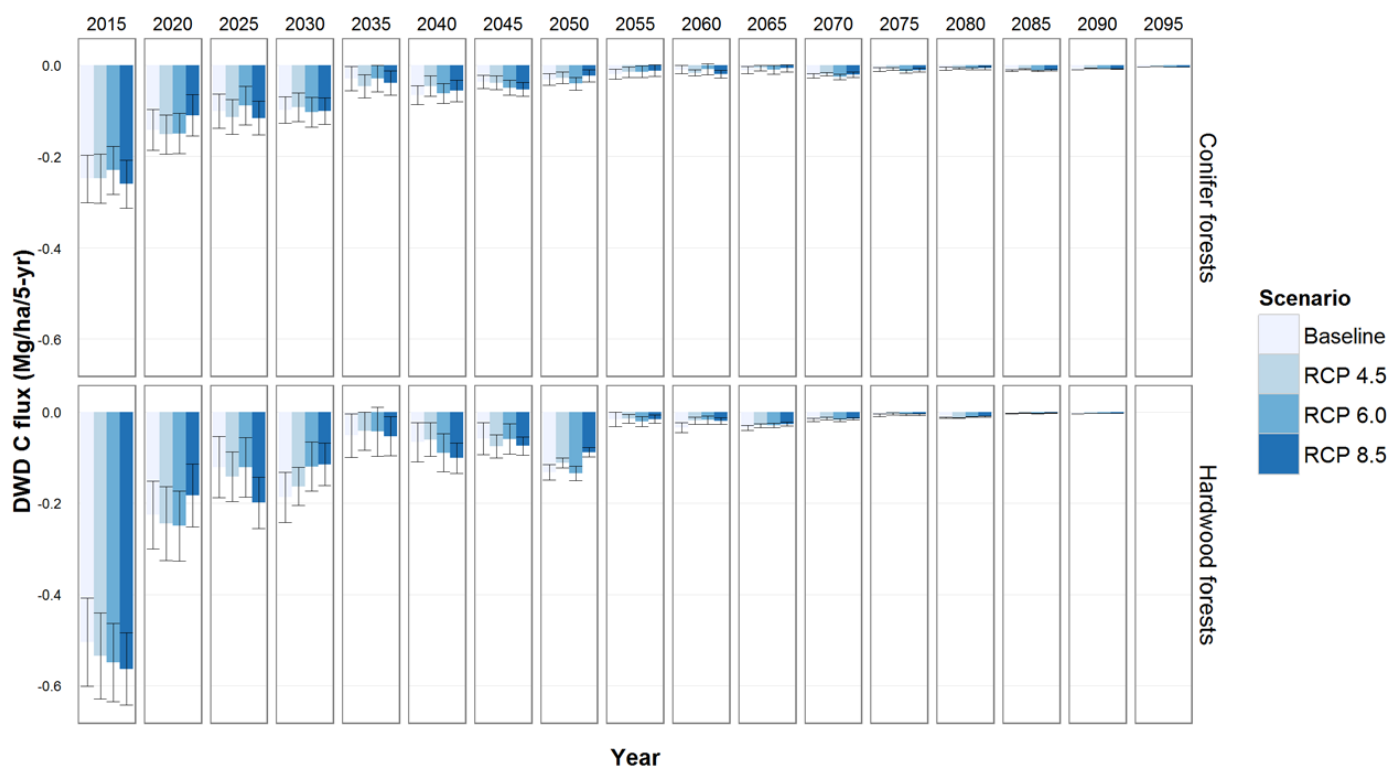

Figure 3. Projected downed woody debris carbon flux initialized using the most recent inventory (2007-2011) in eastern US forests for a baseline current-climate scenario and assuming changes in future climate (based on three RCP scenarios from an ensemble of 17 CMIP5 models and not accounting for future DWD inputs). Error bars indicate \pm one standard error. Conifer forests include loblolly-shortleaf pine, longleaf-slash pine, spruce-fir, white-red-jack pine, and other softwood forest type groups. Hardwood forests include aspen-birch, elm-ash-cottonwood, maple-beech-birch, oak-hickory, and other hardwood forest type groups.

Table 3. Distribution of estimated decreases in downed woody debris residence time (years) by piece size, species group, and region for eastern US forests for a baseline current-climate scenario and assuming changes in future climate for up to 200 years (based on an RCP 6.0 scenario from an ensemble of 17 CMIP5 models).

\begin{tabular}{lllrrrrr}
\hline \multirow{2}{*}{ Species group } & \multirow{2}{*}{ Region } & Length & \multicolumn{5}{c}{ Quantile (years) } \\
\cline { 3 - 7 } & & & Min & 25 & 50 & 75 & Max \\
\hline \multirow{2}{*}{ Conifers } & \multirow{2}{*}{ North } & Short & -9.8 & -7.4 & -4.9 & -4.0 & -0.9 \\
& & Med & -11.4 & -9.9 & -9.4 & -8.6 & -1.2 \\
& Long & -24.5 & -14.2 & -12.0 & -10.6 & -1.9 \\
& \multirow{4}{*}{ South } & Short & -2.8 & -2.4 & -2.0 & -1.8 & -0.7 \\
& & Med & -3.0 & -2.4 & -2.1 & -1.8 & -0.8 \\
& & Long & -5.2 & -2.7 & -2.1 & -1.9 & -0.9 \\
\hline \multirow{2}{*}{ Hardwoods } & \multirow{2}{*}{ North } & Short & -8.8 & -7.1 & -6.6 & -6.0 & -1.4 \\
& & Med & -12.2 & -7.9 & -7.2 & -6.5 & -3.0 \\
& \multirow{4}{*}{ Southyyyyy} & Long & -24.6 & -12.8 & -10.0 & -8.0 & -6.3 \\
& Short & -7.1 & -3.3 & -2.8 & -2.4 & -1.0 \\
& Med & -8.7 & -4.1 & -3.1 & -2.6 & -1.6 \\
& Long & -10.7 & -7.2 & -5.8 & -3.2 & -12.0 \\
\hline
\end{tabular}

number of species, the eastern US was an appropriate region to explore changes in DWD dynamics under future projected climates.

The findings of a shorter residence time for northern hardwoods as opposed to conifers, assuming a baseline scenario, were expected, given our general understanding of species differences in wood decay (Cornwell et al., 2009). The observation of the largest percent difference in residence time change when comparing the RCP 6.0 scenario with that of the baseline for northern hardwoods $(13 \%)$ may be due to greater projected increases in DD5 for the northern compared to southern regions (Fig. 1). The length of DWD pieces will likely further influence DWD residence time if one is interested in a particular species of a general size class (Russell et al., 2014).

Future work merging our results with ecosystem models representing tree growth and mortality in conjunction with DWD dynamics could allow for an array of C flux 
and stock projections (Mazziotta et al., 2014). Moreover, the long-recognized ecological importance of DWD argues for increased empirical and modeling studies that account for the impacts of climate change on this critical component of forest ecosystem functioning (Krajick, 2001; Stokland et al., 2012). The results highlight the need for detailed inventories of DWD so that the stocking in various pools can be assessed with a more accurate quantification of decomposition pathways. Future investigations of DWD decomposition rates should focus on employing climate-related parameters in addition to assessments of local-scale factors (e.g., fungal colonization; Bradford et al., 2014) to examine the response of DWD to potential interactions between altered disturbances and changing climate conditions. Determining how to better incorporate site-specific factors within ecosystem simulations will encourage modelers to investigate the role of local-scale factors in addition to climate for representing DWD decomposition.

We note that these simulations did not account for future DWD inputs - we quantified decomposition trajectories of current DWD C stocks under alternative climate scenarios to characterize temperature effects on DWD dynamics independent of other processes. Particularly when examining $\mathrm{C}$ flux, incorporating the contribution of live-tree $\mathrm{C}$ simultaneously with DWD dynamics will better depict the totalecosystem-C response to changes in climate. Such an approach was recently highlighted by Mazziotta et al. (2014) through their use of a gap-based forest simulation model to forecast changing DWD populations. Given that model parameters for decomposition are largely dependent on temperature in dynamic global vegetation (Cramer et al., 2001), process (Kirschbaum, 1999; Kirschbaum and Paul, 2002), and empirical models that represent DWD decomposition (Crookston et al., 2010; Rebain et al., 2010), there is a need to examine the influence of changing temperatures on woody debris dynamics. A key modeling development would be the incorporation of key forest disturbances common to a region (e.g., windstorms, insect and disease outbreaks) in a stochastic framework, given the linkage with inputs into the standing and DWD pools.

Despite not including $C$ inputs to the DWD pool in this study, emerging research from the same study area suggests that climate change may increase the rate of forest development (i.e., turnover; Zhu et al., 2014). The potentially increased rates of stand development appear to align with our study's projections of increased detrital $\mathrm{C}$ emission and hence elevated DWD turnover. The combination of these two results suggests that the residence time of $\mathrm{C}$ in the major forest ecosystem pools of live and dead biomass will decrease. Although the effect of decreased residence times on the overall sink strength of forest ecosystems will be dependent on future biomass production rates (e.g., longer growing seasons, droughts, and/or $\mathrm{CO}_{2}$ enrichment), it does suggest that managers will have less time to consider management options (Malmsheimer et al., 2008) as forest biomass becomes more transitory. Moreover, given the critical role of DWD as a habitat for a myriad of dead wood-dependent organisms, these future dynamics need to be considered in species vulnerability assessments and action plans, particularly for species requiring habitat elements as refugia during drought and temperature extremes (Amaranthus et al., 1989). Such future dynamics argue for an increasing emphasis on the deliberate retention and creation of DWD habitats in managed landscapes to compensate for accelerated rates of depletion associated with future climate conditions.

\section{The Supplement related to this article is available online at doi:10.5194/bg-11-6417-2014-supplement.}

Acknowledgements. This work was supported by a joint venture agreement established between the US Forest Service, Northern Research Station, and the University of Minnesota, Department of Forest Resources. Additional funding was available from the US Department of Interior Northeast Climate Science Center. We thank Ben Bond-Lamberty, Sabina Burrascano, Christopher Schwalm, John Stanovick, and an anonymous reviewer for comments that helped to improve this work.

Edited by: Y. Kuzyakov

\section{References}

Agresti, A.: An introduction to categorical data analysis (2nd ed.). Wiley, Hoboken, NJ, 400 pp., 2007.

Amaranthus, M. P., Parrish, D. S., and Perry, D. A.: Decaying logs as moisture reservoirs after drought and wildfire, in: E. Alexander (ed.). Stewardship of soil, air and water resources, Watershed 89. R10-MB-77. USDA Forest Service, Region 10, Juneau, Alaska, 191-194, 1989.

Bradford, J., Weishampel, P., Smith, M. L., Kolka, R., Birdsey, R. A., Ollinger, S. V., and Ryan, M. G.: Detrital carbon pools in temperate forests: magnitude and potential for landscape-scale assessment, Can. J. For. Res., 39, 802-813, 2009.

Bradford, M. A., Warren Ii, R. J., Baldrian, P., Crowther, T. W., Maynard, D. S., Oldfield, E. E., Wieder, W. R., Wood, S. A., and King, J. R.: Climate fails to predict wood decomposition at regional scales, Nature Clim. Change, 4, 625-630, 2014.

Brovkin, V., van Bodegom, P. M., Kleinen, T., Wirth, C., Cornwell, W. K., Cornelissen, J. H. C., and Kattge, J.: Plant-driven variation in decomposition rates improves projections of global litter stock distribution, Biogeosciences, 9, 565-576, doi:10.5194/bg-9-5652012, 2012.

Conant, R. T., Ryan, M. G., Ågren, G. I., Birge, H. E., Davidson, E. A., Eliasson, P. E., Evans, S. E., Frey, S. D., Giardina, C. P., Hopkins, F. M., Hyvönen, R., Kirschbaum, M. U. F., Lavallee, J. M., Leifeld, J., Parton, W. J., Megan Steinweg, J., Wallenstein, M. D., Martin Wetterstedt, J. A., and Bradford, M. A.: Temperature and soil organic matter decomposition rates - synthesis of 
current knowledge and a way forward, Glob. Change Biol., 17, 3392-3404, 2011.

Cornwell, W. K., Cornelissen, J. H. C., Allison, S. D., Bauhus, J., Eggleton, P., Preston, C. M., Scarff, F., Weedon, J. T., Wirth, C., and Zanne, A. E.: Plant traits and wood fates across the globe: rotted, burned, or consumed?, Glob. Change Biol., 15, 2431-2449, 2009.

Cramer, W., Bondeau, A., Woodward, F. I., Prentice, I. C., Betts, R. A., Brovkin, V., Cox, P. M., Fisher, V., Foley, J. A., Friend, A. D., Kucharik, C., Lomas, M. R., Ramankutty, N., Sitch, S., Smith, B., White, A., and Young-Molling, C.: Global response of terrestrial ecosystem structure and function to $\mathrm{CO}_{2}$ and climate change: results from six dynamic global vegetation models, Glob. Change Biol., 7, 357-373, 2001.

Crookston, N. L., Rehfeldt, G. E., Dixon, G. E., and Weiskittel, A. R.: Addressing climate change in the forest vegetation simulator to assess impacts on landscape forest dynamics, For. Ecol. Manage., 260, 1198-1211, 2010.

Davidson, E. A. and Janssens, I. A.: Temperature sensitivity of soil carbon decomposition and feedbacks to climate change, Nature, 440, 165-173, 2006.

Edmonds, R. L., Vogt, D. J., Sandberg, D. H., and Driver, C. H.: Decomposition of Douglas-fir and red alder wood in clear-cuttings, Can. J. For. Res., 16, 822-831, 1986.

Fraver, S., Ringvall, A., and Jonsson, B. G.: Refining volume estimates of down woody debris, Can. J. For. Res., 37, 627-633, 2007.

Fraver, S., Milo, A. M., Bradford, J. B., D’Amato, A. W., Kenefic, L., Palik, B. J., Woodall, C. W., and Brissette, J.: Woody debris volume depletion through decay: implications for biomass and carbon accounting, Ecosystems, 16, 1262-1272, 2013.

Giardina, C. P. and Ryan, M. G.: Evidence that decomposition rates of organic carbon in mineral soil do not vary with temperature, Nature, 404, 858-861, 2000.

Harmon, M. E., Cromack Jr., K., and Smith, B. G.: Coarse woody debris in mixed-conifer forests, Sequoia National Park, California, Can. J. For. Res., 17, 1265-1272, 1987.

Harmon, M. E., Ferrell, W. K., and Franklin, J. F.: Effects on carbon storage of conversion of old-growth forests to young forests, Science, 247, 699-702, 1990.

Harmon, M. E., Woodall, C. W., Fasth, B., and Sexton, J.: Woody detritus density and density reduction factors for tree species in the United States: a synthesis. USDA For. Serv. Gen. Tech. Rep. NRS-29. 65 pp., 2008.

Harmon, M. E., Bond-Lamberty, B., Tang, J. W., and Vargas, R.: Heterotrophic respiration in disturbed forests: A review with examples from North America, J. Geophys. Res.-Biogeo., 116, 1-17, 2011a.

Harmon, M. E., Woodall, C. W., Fasth, B., Sexton, J., and Yatkov, M.: Differences between standing and downed dead tree wood density reduction factors: a comparison across decay classes and tree species. USDA For. Serv. Res. Pap. NRS-15, p. 40, 2011 b.

Intergovernmental Panel on Climate Change (IPCC): Climate Change 2013: The Physical Science Basis, Contribution of Working Group I to the Fifth Assessment Report of the Intergovernmental Panel on Climate Change, edited by: Stocker, T. F., Qin, D., Plattner, G.-K., Tignor, M., Allen, S. K., Boschung, J., Nauels, A., Xia, Y., Bex, V., and Midgley, P. M., Cambridge
University Press, Cambridge, United Kingdom and New York, NY, USA, 1535 pp., 2013.

Janisch, J. E., Harmon, M. E., Chen, H., Fasth, B., and Sexton, J.: Decomposition of coarse woody debris originating by clearcutting of an old-growth conifer forest, Ecoscience, 12, 151-160, 2005.

Kirschbaum, M. U. F.: CenW, a forest growth model with linked carbon, energy, nutrient and water cycles., Ecol. Model., 118, 17-59, 1999.

Kirschbaum, M. U. F. and Paul, K. I.: Modelling C and N dynamics in forest soils with a modified version of the CENTURY model, Soil. Biol. Biochem., 34, 341-354, 2002.

Krajick, K.: Defending deadwood, Science, 293, 1579-1581, 2001.

Mackensen, J., Bauhus, J., and Webber, E.: Decomposition rates of coarse woody debris - a review with particular emphasis on Australian species, Aust. J. Bot., 51, 27-37, 2003.

Malmsheimer, R. W., Heffernan, P., Brink, S., Crandall, D., Deneke, F., Galik, C., Gee, E., Helms, J. A., McClure, N., Mortimer, M., Ruddell, S., Smith, M., and Stewart., J.: Forest management solutions for mitigating climate change in the United States, J. For., 106, 115-171, 2008.

Mazziotta, A., Mönkkönen, M., Strandman, H., Routa, J., Tikkanen, O.-P., and Kellomäki, S.: Modeling the effects of climate change and management on the dead wood dynamics in boreal forest plantations, Eur. J. For. Res., 133, 405-421, 2014.

Prescott, C.: Litter decomposition: what controls it and how can we alter it to sequester more carbon in forest soils?, Biogeochemistry, 101, 133-149, 2010.

Radtke, P. J., Amateis, R. L., Prisley, S. P., Copenheaver, C. A., Chojnacky, D. C., Pittman, J. R., and Burkhart, H. E.: Modeling production and decay of coarse woody debris in loblolly pine plantations, For. Ecol. Manage., 257, 790-799, 2009.

Rebain, S. A., Reinhardt, E. D., Crookston, N. L., Beukema, S. J., Kurz, W. A., Greenough, J. A., Robinson, D. C. E., and Lutes, D. C.: (revised 29 Oct. 2013). The Fire and Fuels Extension to the Forest Vegetation Simulator: updated model documentation. Internal Report, Fort Collins, CO: USDA For. Serv., For. Manage. Serv. Cen., 408 pp., 2010.

Rehfeldt, G. E.: A spline model of climate for the western United States, USDA For. Serv. Gen. Tech. Rep. RMRS-165, 2006.

Russell, M. B., Woodall, C. W., Fraver, S., and D'Amato, A. W.: Estimates of coarse woody debris decay class transitions for forests across the eastern United States, Ecol. Model., 251, 22-31, 2013.

Russell, M. B., Woodall, C. W., Fraver, S., D'Amato, A. W., Domke, G. M., and Skog, K. E.: Residence times and decay rates of downed woody debris biomass/carbon in eastern US forests, Ecosystems, 17, 765-777, 2014.

Ryan, M. G., Harmon, M. E., Birdsey, R. A., Giardina, C. P., Heath, L. S., Houghton, R. A., Jackson, R. B., McKinley, D. C., Morrison, J. F., Murray, B. C., Pataki, D. E., and Skog, K. E.: A synthesis of the science on forests and carbon for U.S. forests, Ecological Society of America: Issues in Ecology, 13, 1-16, 2010.

Stokland, J. N., Siitonen, J., and Jonsson, B. G.: Biodiversity in dead wood. Cambridge, UK: Cambridge University Press, p. 509, 2012.

Taylor, K. E., Stouffer, R. J., and Meehl, G. A.: An overview of CMIP5 and the experiment design, B. Am. Meteorol. Soc., 93, 485-498, 2012. 
US Forest Service: Custom climate data requests. Rocky Mountain Research Station, Moscow Laboratory. http://forest.moscowfsl. wsu.edu/climate/customData/ (last accessed 19 October 2014), 2014.

Van Wagner, C. E.: The line-intersect method in forest fuel sampling, For. Sci., 14, 20-26, 1968.

White, M. A., Thornton, P. E., Running, S. W., and Nemani, R. R.: Parameterization and sensitivity analysis of the BIOME-BGC terrestrial ecosystem model: net primary production controls, Earth Interact., 4, 1-85, 2000.

Woodall, C. W. and Monleon, V. J.: Sampling protocols, estimation procedures, and analytical guidelines for down woody materials indicator of the Forest Inventory and Analysis program. US Department of Agriculture, Forest Service Gen. Tech. Rep. NRS-22, p. $68,2008$.

Woodall, C. W., Walters, B. F., Oswalt, S. N., Domke, G. M., Toney, C., and Gray, A. N.: Biomass and carbon attributes of downed woody materials in forests of the United States, For. Ecol. Manage., 305, 48-59, 2013.
Woudenberg, S. W., Conkling, B. L., O’Connell, B. M., LaPoint, E. B., Turner, J. A., and Waddell, K. L.: The Forest Inventory and Analysis Database: database description and users manual version 4.0 for phase 2, US Department of Agriculture, Forest Service Gen. Tech. Rep. RMRS-245, p 339, 2010.

Zhu, K., Woodall, C. W., and Clark, J. S.: Failure to migrate: lack of tree range expansion in response to climate change, Glob. Change Biol., 18, 1042-1052, 2012.

Zhu, K., Woodall, C. W., Ghosh, S., Gelfand, A. E., and Clark, J. S.: Dual impacts of climate change: forest migration and turnover through life history, Glob. Change Biol., 20, 251-264, 2014. 